\title{
A Modified Limberg Flap versus Z Plasty Flap Technique in Management of Recurrent Pilonidal Disease: A Comparative Prospective Study
}

\author{
Asmaa Gaber R. ${ }^{1}$, Mohamed Yousef A. ${ }^{*}$, Mohamed Abdel Shafy Mohamed", \\ Abd-El-Aal A. Saleem², Hassan A. Abdallah², Hamdy M. Husein ${ }^{1}$ \\ ${ }^{1}$ Department of General Surgery, Qena Faculty of Medicine, South Valley University, Qena, Egypt \\ ${ }^{2}$ Department of General Surgery, Faculty of Medicine, Aswan University, Aswan, Egypt \\ Email: *myousef76@gmail.com
}

How to cite this paper: Asmaa Gaber R., Mohamed Yousef A., Mohamed, M.A.S., Saleem, A.-E.-A.A., Abdallah, H.A. and Husein, H.M. (2018) A Modified Limberg Flap versus Z Plasty Flap Technique in Management of Recurrent Pilonidal Disease: A Comparative Prospective Study. Open Access Library Journal, 5: e4715.

https://doi.org/10.4236/oalib.1104715

Received: June 8, 2018

Accepted: July 8, 2018

Published: July 11, 2018

Copyright $\odot 2018$ by authors and Open Access Library Inc.

This work is licensed under the Creative Commons Attribution International License (CC BY 4.0).

http://creativecommons.org/licenses/by/4.0/

\begin{abstract}
Background: There are controversies about the etiology and management of recurrent pilonidal sinus. The numbers of techniques are testament in treating pilonidal sinus (PNS) and no single procedure is superior in all aspects. Aim of the study: The aim of this study was to compare two operative procedures (modified Limberg flap versus $\mathrm{Z}$ plasty flap) in management of recurrent pilonidal sinus, regarding their complications including recurrences of the disease, morbidity, hospital stay, day off work and postoperative complications. Patients and methods. This is comparative prospective study between modified Limberg flap and $\mathrm{Z}$ plasty flap in treatment of recurrent pilonidal sinus. 30 patients were divided into 2 groups: Group (1) treated with modified Limberg flap and group (2) treated with Z plasty, and we followed up the patients in both groups for postoperative complications, hospital stay, day off work, recurrences, patients satisfactions. Results. Operative time, hospital stay duration, complete wound healing was longer in group (2) Z plasty group. Mobilization was early in MLF group than $Z$ plasty group (1 day versus 2 days). Time to return to work, it was $14(12$ - 16) days in MLF groups and 18 (15 $22)$ in $Z$ plasty group $(p<0.001)$. Infection occurred only in one in MLF group (1) and 2 patients in $Z$ plasty group (2). The mean time for complete healing of the wound after Modified Limberg flap group (1) was $16 \pm 4.2$ days while in Z plasty group (2) it was $22 \pm 6.8$ days. Satisfaction score was better in MLF group (1). Recurrence hadn't occurred in any of the patients included in this study during the follow-up period. Conclusion: Both of modified Limberg flap and Z-plasty technique are used to cause flattening of the natal cleft,
\end{abstract}


thus reducing local recurrence rates. So, we recommend use of flap technique for recurrent pilonidal sinus patients; modified Limberg transposition flap is better than $\mathrm{Z}$ plasty flap, because of the less hospital stay time, early return to work, and cosmetically more accepted as it has less postoperative complications. Also $\mathrm{Z}$ plasty flap has a major limitation as it is difficult to apply if there is a wide defect in the horizontal axis.

\section{Subject Areas}

Surgery \& Surgical Specialties

\section{Keywords}

Modified Limberg Flap, Z-Plasty, Recurrent Pilonidal Sinus

\section{Introduction}

Pilonidal sinus is a common benign disease that occurs more commonly in young adults and usually seen in the sacro-coccygeal region and it has negative impact on the quality of life [1]. The term pilonidal is derived from the Latin words pilus (hair) and nidus. It occurs mainly between the ages of 15 - 25 years and affects males more than females and it is rare to see before puberty or after the age of 40 years [2]. Its incidence is 26 per 100,000 people and observed at a rate of $0.7 \%$ in the general population [3]. It presents as an abscess, cyst or sinus tracts with or without purulent discharge in the pre-sacral region [4].

The main complaint of the patients is painless, continuous or periodic discharge. However, with a carefully taken medical history, a large percentage will reveal previously experienced abscesses [5].

The ideal method of pilonidal sinus treatment should have a low recurrence rate with minimum tissue excision, a short hospitalization stay, patient return to his normal life rapidly with small scar, cosmetically accepted and good patient satisfaction, simple and easy to learn [2] [6].

The ideal method of pilonidal sinus disease treatment is still controversial. There are many surgical and conservative (medical) methods used for treatment. The main bases of surgical treatment of pilonidal sinus treatment including surgical excision of the sinus tracts followed by either primary closure, flap procedure or left open the wound for secondary healing. Surgical methods are including simple incision, drainage, unroofing, curettage and spontaneous secondary healing, excision-flap sliding, Karydakis, Bascom methods, modified Limberg flap, Z plasty flap and modified Bascom cleft lift procedures are the most commonly used surgical methods. Conservative methods including phenol solution, the crystallized phenol method, cauterization and alcohol injection have also been used [7]. However, among these treatment methods, an optimal treatment type has not been described yet [8].

Recurrence may be occurred due to many factors; as inadequate excision, deep 
midline clefts, midline scar, presence of a dead space, poor personal hygiene and early wound complications as infection, dehiscence, excessive tension and obesity. So there are many factors implicated in recurrence include inadequate excision, presence of dead space, deep midline gluteal clefts, poor personal hygiene, midline scar early wound complications, excessive tension and obesity [4] [9] [10] [11].

The lowest recurrence rates have been reported for procedures involving local flap reconstruction [12]. There are many different flaps described in the treatment of pilonidal sinus including, Karydakis flap, Z-plasty, Limberg flap, $\mathrm{W}$-plasty, Limberg flap, rotation flap, gluteus maximus musculo-cutaneous flap, sacral adipo-fascial turn-over flap, V-Y fascio-cutaneous advancement flap and skin flap of the cleft lift procedure [2] [3] [9] [11] [12].

The aim of the present study is to compare the modified Limberg flap versus the $\mathrm{Z}$ plasty flap technique in the treatment of recurrent pilonidal disease regarding postoperative complications, hospital stay, days off works, recurrence rates, postoperative cosmetic appearance and patient's satisfactions.

\section{Patients and Methods}

This prospective randomized study was conducted at general surgery department at Qena university hospitals, South Valley University and Aswan university hospitals during the period from September 2015 to December 2017. 30 patients who were treated only for recurrent pilonidal disease were included in this study. Patients with previous surgical procedures, including primary closure were considered to have recurrent disease. 30 patients were divided in to 2 groups: group (1) treated with modified Limberg flap (MLF) and group (2) with Z plasty procedure (ZPF).

Randomization criteria: In this study, patients with recurrent pilonidal sinus were accepted who were between 16 - 40 years of age and without pilonidal sinus abscess or infection.

Inclusion criteria: Presence of recurrent pilonidal sinus, patients willing to give written informed consent, adult (over 16 years of age) with previous surgery of sacrococcygeal pilonidal sinus disease, patients fit for surgery with normal coagulation profile and patients with no infection at time of surgery.

Exclusion criteria: Patients not willing to give informed consent, patients were unfit for surgery, age less than 16 year, patients presented with denovo pilonidal sinus (presented for first time) and patients with chronic medical conditions, such as diabetes mellitus, renal failure, immunosuppression or patients with defect in coagulation profile.

Informed consent was obtained from all patients and this study was approved by local ethics committee.

All patients were subjected to careful history taking: duration of symptoms, previous operations, previous postoperative complications, recurrence time after previous operations, presence or absence of discharge, and preoperative routine 
laboratory investigations.

All patients were prospectively evaluated in terms of age, sex, BMI, duration of preoperative symptoms, location of sinus pits (midline or para-median), numbers of pits (single or multiple) and followed up in postoperative time regarding hospital stay, return to work, postoperative complications (wound dehiscence, infections, hematoma, seroma and cosmetics scars), satisfaction score and recurrence.

All the patients followed up in outpatient's clinic after operation till complete wound healing and removal of suction drain and stitches then every three months for the first postoperative year than yearly after wards unless if there were complaint. If the patient travelled, we contact him by telephone. Follow up period range from 12 months to 30 months.

Procedure: Preoperative preparation included shaving on the day of surgery and broad-spectrum antibiotic on the night before and at start of surgery

Modified Limberg flap method: The operation was performed as described by Mentes et al. [13]. Most of patients in this study were operated under spinal anesthesia in the operating room (only 2 patients requested general anesthesia). After anesthesia, the patients were placed in the prone, jack-knife position, with the buttocks strapped apart using wide adhesive tape, then marking of skin with marker pen to draw modified Limberg flap to pass to other side to centre the flap $1 \mathrm{~cm}$ from midline. The excision was carried down to the fascia overlying the sacrum and laterally to the fascia of the gluteus maximus muscle. Dissection was performed with electro-cautery. Elliptical inverted triangular, rhomboid were used to include all sinuses. After excision, a Limberg flap was prepared from the right or left gluteal region, the subcutaneous tissues was closed with $3 / 0$ polyglactin (Vicryl), and skin with $3 / 0$ prolene interrupted suture and compression dressing was applied. Suction was placed through a separate incision that was located $2 \mathrm{~cm}$ lateral from the initial incision and kept in place until the drainage decreased to less than $10 \mathrm{ml} /$ day (Figures 1-5).

Z-plasty procedure: Steps as modified Limberg except skin flaps were raised and transposed. Each limb of $Z$ was equal in length. Angle of the flaps was roughly equal to $60^{\circ}$. Excision including all pits between marks and closed in $\mathrm{Z}$ shaped flap which was mobilized easily and not under tension (Figures 6-10).

Postoperative management: Included postoperative antibiotics, analgesics, daily dressing and suction was removed when less than $10 \mathrm{ml} /$ day amount. Clinical assessment was performed at the end of $5^{\text {th }}$ postoperative day and 1, 3, 6 months and 12 month following surgery.

Satisfaction score: for performing a patient's satisfaction score we asked, a standard question to every patient: are you satisfied with outcome of your surgical treatment? The answers were scored in a discrete ordinal scale from 1 to 4 with 4 for excellent, 3 good, 2 fair, and 1 poor.

Statistical analysis: We used SPSS (Statistical Package for the Social Sciences ver. 10.0, SPSS Inc, Chicago, Illinois, USA) computer software for Statistical analysis. For all statistical analyses, $\mathrm{p}$ value $<0.05$ was considered significant. 


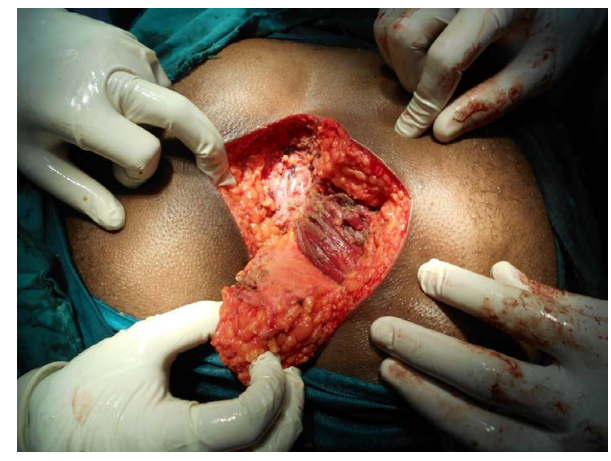

Figure 1. During excision of sinuses during modified Limberg flap.

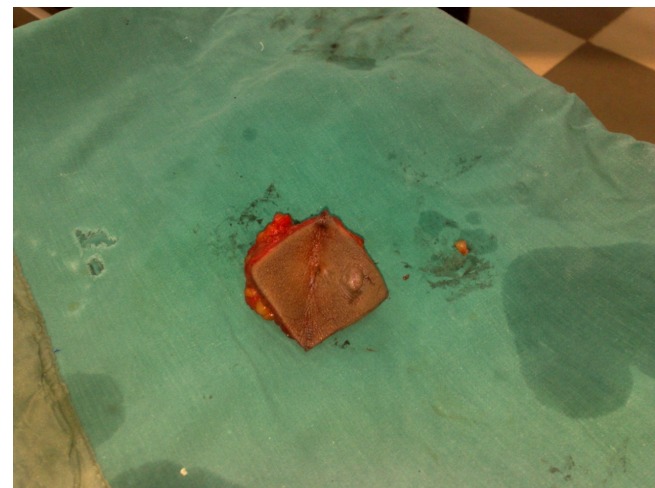

Figure 2. Flap excision

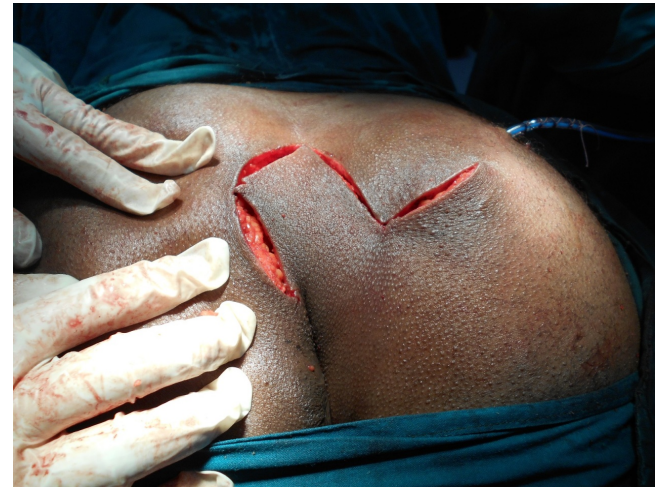

Figure 3. Modified Limberg flap closure.

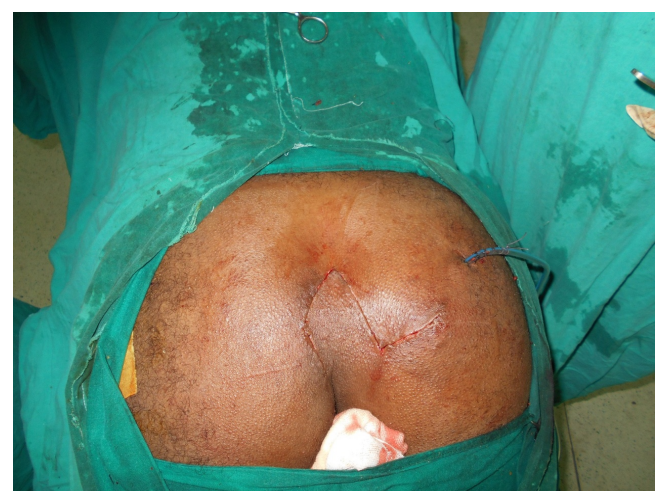

Figure 4. After closure of MLF. 


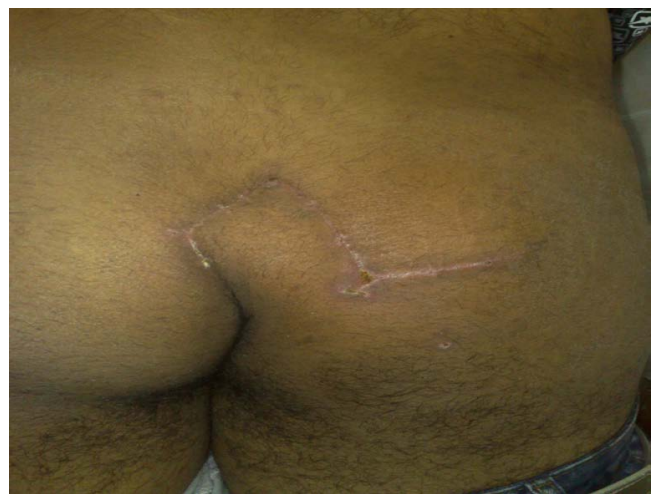

Figure 5. Postoperative follow up after 2 months.

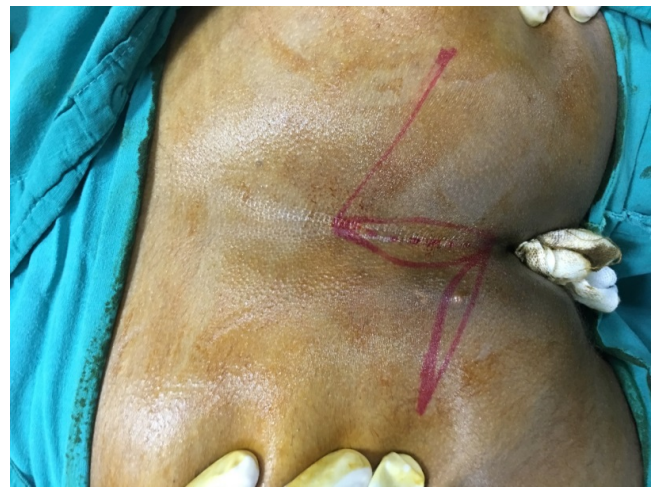

Figure 6. Marking Of the site of incision for $\mathrm{Z}$ plasty.

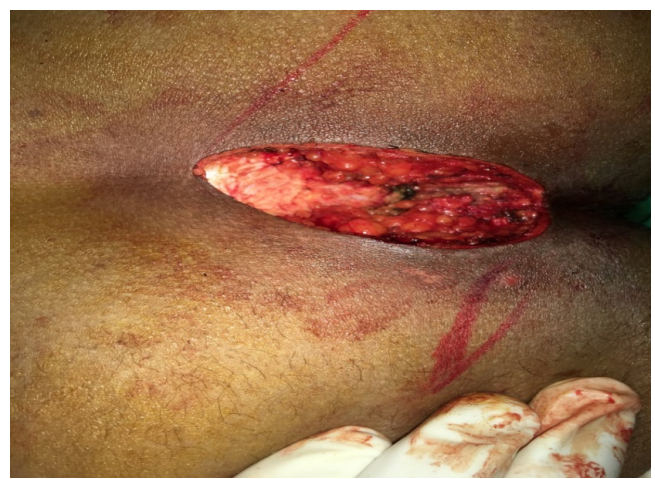

Figure 7. Excison of the pilonidal sinous.

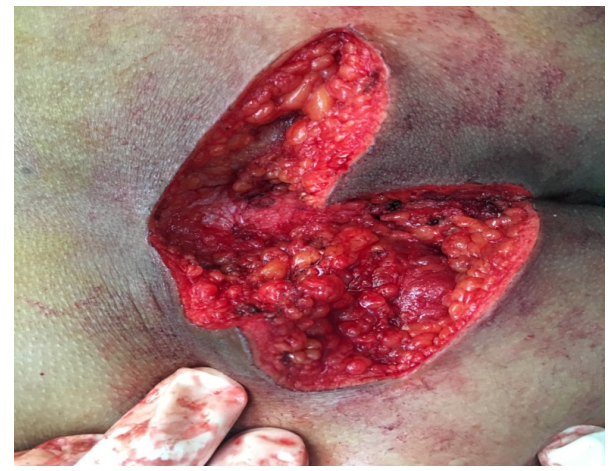

Figure 8. Excision of the pilonidal sinus and creating the flaps for $\mathrm{Z}$ plasty. 


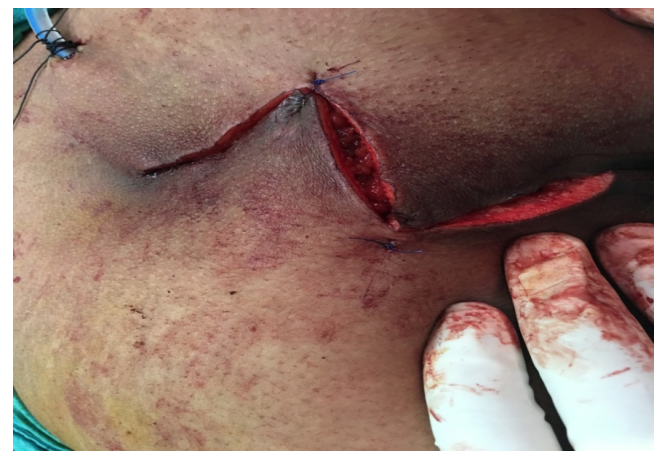

Figure 9. Closing Z plasty.

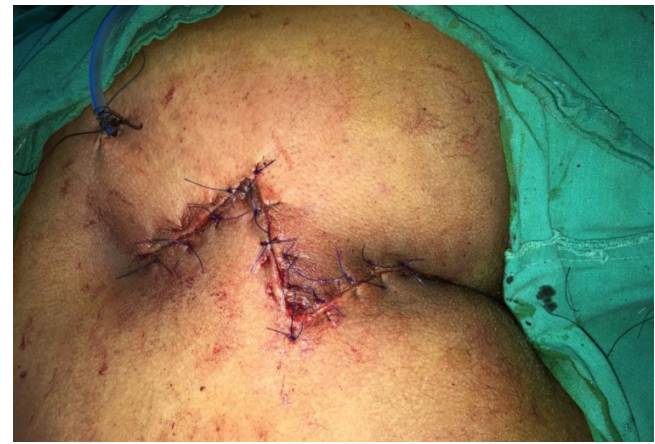

Figure 10. After Closure of Z plasty.

\section{Results}

30 patients were included in this study from September 2015 to December 2017, of whom 15 patients were treated using the modified Limberg flap procedure and 15 patients were treated using the $\mathrm{Z}$ plasty procedure. Ages of both groups ranges from 16 to 45 years with mean age in MLF group (1) about 23 years and 24 years in Z plasty group (2). Most patients of both groups were males only 4 females in group (1) and one female in group (2).

There were no significant difference between the two groups in age, body mass index, sinus pits location or presence of multiple or single pits $(p>0.05)$ but most pits were multiple and in midline in both groups. Preoperative durations of symptoms were nearly equal in both groups with ranges from $9-12$ months with average 11 months. The main complaints in both groups were pain then discharges and there were no significant difference between both groups regarding preoperative complaints. $60 \%$ of patients with recurrent disease in our study were overweight (BMI: 25 - 29).

Regarding operative time, there were significant difference between both groups as it was longer in $\mathrm{Z}$ plasty group (2) than modified Limberg group (1) also hospitalization was longer in Z plasty group (2) than MLF group (1). Mobilization were early in MLF group than $Z$ plasty group as mean time to first mobilization was earlier in MLF group (1) than Z plasty group (2) (1 day versus 2 days ) with mean $(1-1)$ day vs. $2(1-3)$ days, respectively: $p<0.001$.

As regarding suction drain usage, removal of suction drain were early in MLF 
group (1) than Z plasty group (2) but without significant statistical difference. As regarding return to work, it was 14 (12 - 16) days in MLF group (1) and 18 (15 22) days in $Z$ plasty group (2) ( $p<0.001)$. Satisfaction score were good to excellent in MLF group (1) better than in group (2) (Z plasty) which were poor to good.

As regarding postoperative complications: only one patient had infections in MLF group (1) and 2 patients in Z plasty group (2). Seroma not occurred in any patient in MLF group (1) and occurred in 2 patients in Z plasty group (2) which treated conservatively without intervention. Wound dehiscence had occurred only in one patient in Z plasty group (2) and treated successfully with daily dressing. As regarding flaps: partial flap ischemia were occurred in one patient in MLF group (1) and three patients in Z plasty group (2) and treated conservatively but total flap necrosis did not occur in any patient in both groups and flap edema had occurred in one patient in the MLF group (1) and two patients in group (2) so regarding flaps, there were no statistical difference in flap complications; just complications were lower in group (1) than group (2).

The mean time for complete healing of the wound after modified Limberg flap group (1) were $16 \pm 4.2$ days while in $\mathrm{Z}$ plasty group (2) were $22 \pm 6.8$ days and irregular scar formation occurred only in one patient in group (1) and 4 patients in group (2). When patient's satisfaction for postoperative cosmetic appearances was compared, there was a good acceptance from patients for modified Limberg scars than Z plasty scars. Recurrence hadn't occurred in any of the patients included in this study during the follow-up period (Table $1 \&$ Table 2).

Table 1. Clinical comparison between 2 groups.

\begin{tabular}{|c|c|c|c|}
\hline Parameter & $\begin{array}{l}\text { Modified Limberg } \\
\text { flap group (1) }\end{array}$ & $\begin{array}{l}\mathrm{Z} \text { plasty flap } \\
\text { group (2) }\end{array}$ & $P$ value \\
\hline No of patients in each group & 15 & 15 & \\
\hline $\operatorname{Sex}(M / F)$ & $11 / 4$ & $14 / 1$ & 0.765 \\
\hline Age (years) & 23 & 24 & 0.231 \\
\hline \multicolumn{4}{|l|}{ Site } \\
\hline Midline single & 3 & 4 & \\
\hline Midline multiples & 11 & 10 & \\
\hline Para-midline & 1 & 2 & \\
\hline Duration of preoperative complaints (months) & $10.45 \pm 3.2$ & $11.34 \pm 9.45$ & 0.07 \\
\hline \multicolumn{4}{|l|}{ Main Complaint } \\
\hline -pain & 13 patients $(86.6 \%)$ & 12 patients $(80 \%)$ & 0.874 \\
\hline -discharges & 10 patients $(66.6 \%)$ & 11 patients $(73 \%)$ & 0.16 \\
\hline \multicolumn{4}{|l|}{ Obesity } \\
\hline -Average BMI $<25$ & 3 & 2 & \\
\hline -Overweight (BMI 25 - 29.9) & 9 & 8 & 0.543 \\
\hline -Obese (BMI 30 - 39.9) & 3 & 4 & \\
\hline -Morbidly obese (BMI $\geq 40$ ) & 0 & 1 & \\
\hline
\end{tabular}


Table 2. Operative and postoperative outcomes.

\begin{tabular}{|c|c|c|c|}
\hline Parameter & $\begin{array}{l}\text { Modified Limberg } \\
\text { flap group (1) }\end{array}$ & $\begin{array}{c}\text { Z plasty } \\
\text { flap group (2) }\end{array}$ & $P$ value \\
\hline Duration of operation (minutes) & $52(45-70)$ & $75(60-90)$ & $<0.001$ \\
\hline First mobilization(day) & $1(1-1)$ & $2(1-3)$ & $<0.001$ \\
\hline Painless toilet seating (days) & $1(1-2)$ & $2(1-3)$ & $<0.001$ \\
\hline Drain usage & $5.71 \pm 2.5$ & $7.68 \pm 1.9$ & 0.346 \\
\hline Length of hospital stay (days) & $1.6(1-4)$ & $3.4(3-7)$ & $<0.001$ \\
\hline Time return to work & $10(8-15)$ & $18(14-22)$ & $<0.001$ \\
\hline Pain VAS score & $2(1-3)$ & $5(2-6)$ & $<0.001$ \\
\hline Complete healing time (day) & $16(14-24)$ & $22(18-28)$ & $<0.001$ \\
\hline Patient satisfaction score & $3.2 \pm 0.66$ & $1.9 \pm 0.7$ & $<0.001$ \\
\hline Follow up (months) & $14 \pm 8.6$ & $15 \pm 7.8$ & 0.656 \\
\hline \multicolumn{4}{|l|}{ Complications } \\
\hline -Wound infection & 1 & 1 & \\
\hline -Seroma & 0 & 2 & 0.356 \\
\hline -Flap oedema & 1 & 2 & 0.590 \\
\hline -partial flap ischemia & 1 & 3 & 0.358 \\
\hline -Flap necrosis & 0 & 0 & \\
\hline -Partial wound dehiscence & 1 & 3 & 0.380 \\
\hline -Total wound dehiscence & 0 & 0 & \\
\hline -Irregular scar formation & 1 & 4 & $<0.001$ \\
\hline -Recurrence rate & 0 & 0 & \\
\hline
\end{tabular}

\section{Discussion}

Pilonidal sinus was described by Anderson in 1847 and by Hodges in 1880 [14] [15]. Pilonidal as a word means "a nest of hair". Pilonidal sinus disease PSD is a benign chronic condition start with localized inflammation with abscess formation causing fistulae, sinuses, chronic inflammation and discharge. It may occur in many sites as axilla, umbilicus and interdigital but it is usually seen in the sacrococcygeal region (natal cleft), although it is chronic but often present with acute exacerbations [16]. In past, it was thought to be a congenital disease but recently it is more accepted to be an acquired condition [2]. It is mainly occurs in young age and more common in males than in females (Male/Female $=4-$ 5/1) [17]. According to Gurer et al. [18], he reported a mean patient age of 25.5 and a gender balance of $95 \%$ males in a series about pilonidal sinus disease.

In our study, mean age in both groups were 23 and 24 years respectively with range from 16 to 45 years and M: F were 6:1with percentage 84\%, although our study in recurrent group only, but also many studies confirm that the disease is predominant in males [19] [20]. Although, it is benign chronic disease but because it occurs in young adults in their main productive age so it has a negative impact on the socioeconomic condition, general economy and financial state 
because it causes loss of work time especially during acute exacerbations [8].

There are many risk factors implicated in occurrence of PND including family history, local trauma, obesity, sedentary occupation, and poor body hygiene. There are many factors contributing in recurrences as postoperative complications, obesity, smoking, size of sinus and previous procedure used [13].

In the literature, there are two options have been used for in the treatment of PND, either conservative medical methods or surgical treatment. Medical treatment options include alcohol, phenol and silver nitrate injection into the cavity. Surgical treatment methods include curettage after siusotomy, excision and leaving an open for secondary intention or marsupialized wound after excision, excision and primary closure, Bascom procedure, Karydakis flap procedure $(\mathrm{KF})$, or sinus excision and skin flap methods, such as Limberg flap rotation (LF), Z plasty flap and modified Limberg flap. Surgical treatment is the most preferred methods [21] [22].

The use of complex plastic flaps for cleft obliteration is preferable in recurrent pilonidal sinus. There is a disadvantage in surgical treatment of PND in general as it is operator dependent. There is controversy about the ideal procedure for the treatment. The ideal treatment methods should be resulted in rapid wound healing, short hospital stay, short period of work off days as most of patient are young adult and working, less wound complications as seroma, dehiscence, infection, low recurrence rate, good patient satisfactions and good cosmetic results [11] [23] [25]. So the main goal in management of pilonidal sinus should aim to complete excision of the sinuses and all pits with their ramifications, prevent wound complications that can result in recurrence, create an eccentric suture line, obliteration the natal cleft by using various flap techniques, improve local hygiene, and prevent hair re-growth in the site of the repair by always shaving hair in this area or any methods of hair ablation [11].

Recurrence is the main problem in the treatment of pilonidal sinus and may be occur due to inadequate excision, presence of dead space, deep midline gluteal clefts, poor personal hygiene, midline scar, early postoperative wound complications, excessive tension and obesity [9] [11] [12] [13] [25]. The lowest recurrence rates have been re-ported for procedures using local flap rotation. There are many flaps used in the treatment of recurrent pilonidal sinus as Z-plasty, W-plasty, Karydakis flap, Limberg flap, modified Limberg flap, rotation flap, gluteus maximus musculo-cutaneous flap, sacral adipo-fascial turn-over flap, cleft lift procedure and V-Y fascio-cutaneous advancement flap. In the literature, recurrence rates with flap procedures were ranging between zero and 6\% - 8\% [11] [23] [26] [27] [28].

In this present study we were prospectively compared between two flap procedures in treatment of recurrent pilonidal sinus disease (modified Limberg flap versus $\mathrm{Z}$ plasty flap). As both techniques not only cover the wound but also result in flattening of the natal cleft and decrease hair accumulation, decrease the mechanical irritation with low recurrence rates [9]. So both flaps had lowest 
recurrence rates repotted in literature and this is important in the procedure used but our study we focused on other important factors sometimes neglected in many comparative study as hospital stay, time off work and patients satisfactions.

30 patients were conducted at general surgery department at Qena university hospitals; South Valley University and Aswan university hospitals during the period from September 2015 to December 2017 with recurrent pilonidal disease were included in this study and divided in to 2 groups: group (1) treated with modified Limberg flap (MLF) and group (2) with Z plasty procedure.

We found that most of patients were young adults, and most of them were males which as present in literature, in modified Limberg flap female patients were 4 more than $\mathrm{Z}$ plasty because after their counseling they preferred Limberg flap than plasty flap as they had thought that it is cosmetically better than $\mathrm{Z}$ plasty. As regarding operative time, hospital stay, time off work, postoperative complications, satisfaction score, modified Limberg flap was better than $\mathrm{Z}$ plasty.

As regarding recurrences, we not observed any recurrences in both groups. As regard recurrence rates and complications in other studies or which reported in literature, we found that Kapan et al. reported that modified Limberg flap rotation is preferred for safety reasons given its low recurrence and complication rates especially in patients with recurrence and multiple pits and sinuses, lateral flap rotations are combined with removing the midline [9]. Mentes et al. [13], Ersoy et al. [24] reported that modified Limberg flaps had lower recurrence and complication rates than $\mathrm{Z}$ plasty in their studies. The reported recurrence rate for modified Limberg flap varies from $0.8 \%$ to $2.7 \%$ [29]. Topgul et al. [30] operated on 200 patients, and the recurrence rate was found to be $2.5 \%$. Daphan et al. [31] operated on 147 patients with a median follow-up time of 13.1 months, and recurrence was noted in $4.8 \%$ of patients, although in our series, no recurrence was observed in either groups in the follow up period and this may attributed to small number of patients in our study, or due to effectiveness of the both procedures, or follow up time were shorter.

Although recurrences are the most important factor in treatment of pilonidal sinus disease but also there are many other important factors in the treatment of pilonidal sinus with surgical procedures as postoperative pain, hospital stay, return to daily activities, time off work, and patient cosmetic satisfaction especially in recurrence with large defects, as flap procedures can reduce aesthetic satisfaction because it result in an irregular scar. As regarding durations of hospital stay Urhan et al. [23] reported that the mean duration of hospital stay after modified Limberg flap was 3.7 days and Kapan et al. [9] reported duration of 5.3 days. In our study we found that hospital stay time were $1.6(1-4)$ days in MLF group (1) lower than $3.4(3-7)$ days in $\mathrm{Z}$ plasty group (2) $(\mathrm{p}=0.001)$. Omer Mentes et al. [19] had reported that the Limberg flap group provided better postoperative pain score (visual analogue scale: VAS), complications rate, time to discontinuation of analgesics, and painless sitting than the $\mathrm{Z}$ plasty group and Ersoy et al. 
[24] found similar results. In our study, MLF group had a lower VAS score (2 vs. 5), higher patient satisfactions ( $3.2 \pm 0.66$ vs. $1.9 \pm 0.7)$, earlier first mobilization ( 1 vs. 2 days) and more painless toilet sitting ( 1 vs. 2 days). These patients also had shorter complete healing time (22/24 day) than the $\mathrm{Z}$ plasty group ( $\mathrm{p}<$ 0.001).

A Cochrane overview has been performed to provide evidence-based guidance for surgical treatment. The review concluded that off-midline closure (including modified Limberg flap, Karydakis and Bascom flaps natal cleft, $\mathrm{Z}$ plasty) is the best choice for primary and recurrent pilonidal sinus [28].

\section{Conclusion}

From results of this present study, we found that Limberg flap procedure is a safe choice for the surgical Treatment of recurrent sacrococcygeal pilonidal sinus disease due to its low complication rate, short length of hospital stay and early return to work, low VAS score, high patient satisfaction and shorter complete healing duration. Therefore, we recommend modified Limberg flap procedure as a good option for the treatment of recurrent pilonidal sinus disease. Also $\mathrm{Z}$ plasty flap has a major limitation as it is difficult to apply if there is a wide defect in the horizontal axis.

\section{Conflict of Interest}

Authors declare no conflict of interest.

\section{Ethical Consideration}

This study was approved by local ethics committee.

\section{References}

[1] Hull, T.L. and Wu, J. (2002) Pilonidal Disease. Surgical Clinics of North America, 82, 1169-1185. https://doi.org/10.1016/S0039-6109(02)00062-2

[2] McCallum, I.J., King, P.M. and Bruce, J. (2008) Healing by Primary Closure versus Open Healing after Surgery for Pilonidal Sinus: Systematic Review and Meta-Analysis. BMJ, 336, 868-871. https://doi.org/10.1136/bmj.39517.808160.BE

[3] Aslam, M.N., Shoaib, S. and Choudhry, A.M. (2009) Use of Limberg Flap for Pilonidal Sinus-A Viable Option. Journal of Ayub Medical College Abbottabad, 21, 31-33.

[4] Onder, A., Girgin, S., Kapan, M., Toker, M., Arikanoglu, Z., Palanci, Y., et al. (2012) Pilonidal Sinus Disease: Risk Factors for Postoperative Complications and Recurrence. International Surgery, 97, 224-229. https://doi.org/10.9738/CC86.1

[5] Eryilmaz, R., Sahin, M., Alimoğlu, O. and Kaya, B. (2003) The Comparison of Incision and Drainage with Skin Excision and Curettage in the Treatment of Acute Pilonidal Abscess. Ulus Travma Acil Cerrahi Derg, 9, 120-123.

[6] Bayhan, Z., Zeren, S., Duzgun, S.A., Ucar, B.I., Alparslan Yumun, H.N. and Mestan, M. (2016) Crystallized Phenol Application and Modified Limberg Flap Procedure in Treatment of Pilonidal Sinus Disease: A Comparative Retrospective Study. Asian Journal of Surgery, 39, 172-177. https://doi.org/10.1016/j.asjsur.2015.12.007 
[7] Girgin, M. and Kanat, B.H. (2014) Te Results of a One-Time Crystallized Phenol Application for Pilonidal Sinus Disease. Indian Journal of Surgery, 76, 17-20. https://doi.org/10.1007/s12262-012-0548-y

[8] Kayaalp, C., Olmez, A., Aydin, C., Piskin, T. and Kahraman, L. (2010) Investigation of a One-Time Phenol Application for Pilonidal Disease. Medical Principles and Practice, 19, 212-215. https://doi.org/10.1159/000285291

[9] Kapan, M., Kapan, S., Pecmezci, S. and Durgun, V. (2002) Sacrococcygeal Pilonidal Disease with Limberg Flap Repair. Techniques in Coloproctology, 6, 27-32. https://doi.org/10.1007/s101510200005

[10] Onishi, K. and Maruyama, Y. (2001) Sacral Adipofascial Turn-Over Flap for the Excisional Defect of Pilonidal Sinus. Plastic and Reconstructive Surgery, 108, 2006-2610. https://doi.org/10.1097/00006534-200112000-00026

[11] Karydakis, G.E. (1992) Easy and Successful Treatment of Pilonidal Sinus after Explanation of Its Causative Process. Australian and New Zealand Journal of Surgery, 62, 385-389. https://doi.org/10.1111/j.1445-2197.1992.tb07208.x

[12] Sondenaa, K., Diab, R., Nesvik, I., et al. (2002) Influence of Failure of Primary Wound Healing on Subsequent Recurrence of Pilonidal Sinus. Combined Prospective Study and Randomized Controlled Trial. European Journal of Surgery, 168, 614-618. https://doi.org/10.1080/11024150201680007

[13] Mentes, B.B., Leventoglu, S., Cihan, A., Tatlicioglu, E., Akin, M. and Oguz, M. (2004) Modified Limberg Transposition Flap for Sacrococcygeal Pilonidal Sinus. Surgery Today, 34, 419-423.

[14] Anderson, A.W. (1847) Hair Extracted from an Ulcer. The Boston Medical and Surgical Journal, 36, 74.

[15] Hodges, R.M. (1880) Pilo-Nidal Sinus. The Boston Medical and Surgical Journal, 103, 485-486. https://doi.org/10.1056/NEJM188011181032101

[16] Surrell, J.A. (1994) Pilonidal Disease. Surgical Clinics of North America, 74, 1309-1315.

[17] Akinci, O.F., Kurt, M., Terzi, A., Atak, I., Subasi, I.E. and Akbilgic, O. (2009) Natal Cleft Deeper in Patients with Pilonidal Sinus: Implications for Choice of Surgical Procedure. Diseases of the Colon \& Rectum, 52, 1000-1002. https://doi.org/10.1007/DCR.0b013e31819f6189

[18] Gurer, A., Gomceli, I., Ozdogan, M., Ozlem, N., Sozen, S. and Aydin, R. (2005) Is Routine Cavity Drainage Necessary in Karydakis Flap Operation? A Prospective, Randomized Trial. Diseases of the Colon \& Rectum, 48, 1797-1799. https://doi.org/10.1007/s10350-005-0108-7

[19] Mentes, O., Bagci, M., Bilgin, T., Ozgul, O. and Ozdemir, M. (2008) Limberg Flap Procedure for Pilonidal Sinus Disease: Results of 353 Patients. Langenbeck's Archives of Surgery, 393, 185-189.

[20] Siddiqui, S.S. and Khan, M.A. (2008) Pilonidal Sinus: Flowing the Aristotelian Middle. Pakistan Journal of Medical Sciences, 24, 845-848.

[21] Sondenaa, K., Andersen, E., Nesvik, I. and Søreide, J.A. (1995) Patient Characteristics and Symptoms in Chronic Pilonidal Sinus Disease. International Journal of Colorectal Disease, 10, 39-42. https://doi.org/10.1007/BF00337585

[22] Bascom, J. (2008) Surgical Treatment of Pilonidal Disease. BMJ, 336, 842-843. https://doi.org/10.1136/bmj.39535.397292.BE

[23] Urhan, M.K., Kücükel, F., Topgul, K., Ozer, I. and Sari, S. (2002) Rhomboid Excision and Limberg Flap for Managing Pilonidal Sinus: Results of 102 Cases. Diseases 
of the Colon \& Rectum, 45, 656-659. https://doi.org/10.1007/s10350-004-6263-4

[24] Ersoy, E., Devay, A.O., Aktimur, R., Doganay, B., Ozdoğan, M. and Gündoğdu, R.H. (2009) Comparison of the Short-Term Results after Limberg and Karydakis Procedures for Pilonidal Disease: Randomized Prospective Analysis of 100 Patients. Colorectal Disease, 11, 705-710. https://doi.org/10.1111/j.1463-1318.2008.01646.x

[25] Onishi, K. and Maruyama, Y. (2001) Sacral Adipofascial Turn-Over Flap for the Excisional Defect of Pilonidal Sinus. Plastic and Reconstructive Surgery, 108, 2006-2010. https://doi.org/10.1097/00006534-200112000-00026

[26] Khatri, V., Espinosa, M.H. and Amin, A.K. (1994) Management of Recurrent Pilonidal Sinus by Simple V-Y Fasciocutaneous Flap. Diseases of the Colon \& Rectum, 37, 1232-1235. https://doi.org/10.1007/BF02257787

[27] Spychała, A. and Murawa, D. (2014) The Limberg Flap Procedure in the Treatment of Pilonidal Cyst Disease of the Sacrum-Initial Report. Polish Journal of Surgery, 86, 257-262. https://doi.org/10.2478/pjs-2014-0046

[28] Sit, M., Aktas, G. and Yilmaz, E.E. (2013) Comparison of the Three Surgical Flap Techniques in Pilonidal Sinus Surgery. The American Surgeon, 79, 1263-1268.

[29] Can, M.F., Sevinc, M.M., Hancerliogullari, O., Yilmaz, M. and Yagci, G. (2010) Multicenter Prospective Randomized Trial Comparing Modified Limberg Flap Transposition and Karydakis Flap Reconstruction in Patients with Sacrococcygeal Pilonidal Disease. American Journal of Surgery, 200, 318-327.

https://doi.org/10.1016/j.amjsurg.2009.08.042

[30] Topgul, K., Ozdemir, E., Kilic, K., Gokbayir, H. and Ferahkose, Z. (2003) Long-Term Results of Limberg Flap Procedure for Treatment of Pilonidal Sinus: A Report of 200 Cases. Diseases of the Colon \& Rectum, 46, 1545-1548. https://doi.org/10.1007/s10350-004-6811-y

[31] Daphan, C., Tekelioglu, M.H. and Sayilgan, C. (2004) Limberg Flap Repair for Pilonidal Sinus Disease. Diseases of the Colon \& Rectum, 47, 233-237.

https://doi.org/10.1007/s10350-003-0037-2 